\title{
Antinociceptive, antiinflammatory, and antipyretic effects induced by the venom of Egyptian scorpion Androctonus amoreuxi
}

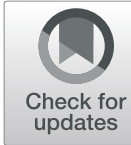

\author{
Nahla M. Shoukry ${ }^{1}$, Mohamed L. Salem², Wafaa K. Teleb', Mohamed M. Abdel Daim³ and \\ Mohamed A. Abdel-Rahman ${ }^{4^{*}}$ (iD
}

\begin{abstract}
Background: Scorpion venom is a very complicated mixture of various peptides/proteins which could induce toxicological and pharmacological responses. This investigation was conducted to evaluate the possible pharmacological properties (analgesic, antipyretic, and antiinflammatory effects) of the Egyptian scorpion venom Androctonus amoreuxi in mice and rats injected intraperitoneally with $1 / 10$ and $1 / 5 L_{50}(0.11$ and $0.22 \mathrm{mg} / \mathrm{kg}$ for mice; 0.385 and $0.77 \mathrm{mg} / \mathrm{kg}$ for rats, respectively).

Results: The peripheral and central analgesic effect of $A$. amoreuxi venom was determined using the tests of miceabdominal writhing and tail immersion of rats, respectively. The antipyretic and antiinflammatory activities were examined using the pyrexia rats model induced by Brewer's yeast and the paw mice edema induced by carrageenan, respectively. The venom of $A$. amoreuxi produced significant $(p<0.05)$ peripheral and central analgesic activity in both animal models. Also, treatment with the scorpion venom showed significant $(p<0.05)$ dose-independent reduction in pyrexia of rats. More importantly, the venom significantly inhibited mice paw edema induced by carrageenan.

Conclusion: Accordingly, the present results showed that the venom of this scorpion possesses remarkable pharmacological properties (analgesic, antipyretic, and antiinflammatory activities) on animal models, and might be contain certain peptides responsible for the reported activities.
\end{abstract}

Keywords: Androctonus amoreuxi, Animal models, Pyrexia, Inflammation, Edema, Pain, Scorpion venom, Tail immersion test, Writhing test

\section{Background}

The limitations of available analgesic and antiinflammatory therapeutic agents stimulated searching for other new molecules (from different sources) able to relief pain, inflammation, and fever. Currently, the animal venoms (such as snake, marine conus, frog, spider, and scorpion toxins) are considered as one of the main sources for the discovery of these compounds (with high selectivity and therapeutic index; Rajendra, Armugam, \& Jeyaseelan, 2004; Altawil, Abdel-Rahman, El-Naggar, El-Khayat, \&

\footnotetext{
*Correspondence: mohamed_hassanain@science.suez.edu.eg

${ }^{4}$ Zoology Department, Faculty of Science, Suez Canal University, Ismailia 41522, Egypt

Full list of author information is available at the end of the article
}

Abdel-Daim, 2015; Safavi-Hemami, Brogan, \& Olivera, 2019). Scorpion venom is a rich source of several biologically active molecules (Abdel-Rahman, Harrison, \& Strong, 2015; Harrison, Abdel-Rahman, Strong, Tawfik, \& Miller, 2016) with various pharmacological properties including antitumor (Elrayess et al., 2019; Ghosh, Roy, Nandi, \& Mukhopadhyay, 2019; Mamelak, 2011), analgesic (Chen \& Ji, 2002; Shao et al., 2007), antiepileptic (Wang et al., 2001; Yu, Zhang, Wang, \& Liu, 1992), and antimicrobial (ElBitar et al., 2019; Harrison, Abdel-Rahman, Miller, \& Strong, 2014; Harrison et al., 2016) activities. The whole body of Chinese scorpion Buthus martensi Karsch (BmK) or its venom has been found to be effective in treating certain neurological disorders (such as hemiplegia, facial 
paralysis, apoplexy, cerebral palsy, and epilepsy), nerve soothing, and as pain killers (especially pains induced by rheumatism and meningitis; Liu et al., 2003). For example, the venom peptides of BmK IT-AP, BmK dIT-AP3, and BmK AngP1 which isolated from the scorpion BmK induced potent analgesic effect in mice and rats (Chen \& Ji, 2002; Guan, Wang, Wang, \& Wang, 2001a; Guan, Wang, Wang, \& Wang, 2001b; Xiong et al., 1999). Similarly, the venom toxin of BmK AS1 induced strong central and peripheral antinociceptive effects on rats. Shao et al. (2013) demonstrated that BmK AGAP-SYPU2 is a scorpion neurotoxin with analgesic and antitumor activities. BmK AGAP-SYPU2 showed analgesic activity in a hot-plate test like morphine (except for its longer duration). The crude venom of Heterometrus laoticus venom (9.5 and $19 \mathrm{mg} /$ $\mathrm{kg}$ ) showed both antinociceptive (using tail immersion and writhing tests) and antiinflammatory activity (using carrageenan test) (Hoang et al., 2014).

There are several scorpion species $(n=24)$ inhabiting Egypt including the Buthidae scorpion of $A$. amoreuxi. Previously, the venom of this species exhibited strong anticancer (Salem, Shoukry, Teleb, Abdel-Daim, \& Abdel-Rahman, 2016) and antimicrobial (Almaaytah et al., 2012; Estrada-Gómez, Gomez-Rave, VargasMuñoz, \& van der Meijden, 2017) activities using in vivo and in vitro studies. The present work was conducted to extend our earlier pharmacological study (Salem et al., 2016) through investigating the antinociceptive, antipyretic, and anti-inflammatory effects of the Egyptian scorpion venom $A$. amoreuxi in both rats and mice animal models.

\section{Methods}

Collection of scorpion venom and experimental animals The scorpion specimens $(n=200)$ were collected from the Western Costal Desert (Alexandria Governorate, Egypt). The scorpion venom was electrically collected $(12-16 \mathrm{~V}, 3 \mathrm{~ms})$, freeze-dried and kept in $-20{ }^{\circ} \mathrm{C}$ until use (Abdel-Rahman, Quintero-Hernández, \& Possani, 2013). All experimental animals (128 male adult albino rats and mice) used in this investigation and experimental protocols were verified (Guide for the Care and Use of Laboratory Animals) and approved (number: 201503) by the Committee of Suez Canal University for Research Ethics. The animals were housed in plastic cages $(26 \pm 2$ ${ }^{\circ} \mathrm{C}$; 75-80\% humidity; 12-h light/darkness cycle) and fed with standard diet and water ad libitum. After the end of experimentation (section methods 2.3.1, 2.3.2, 2.4, and 2.5.1), rats and mice were returned to the animal house (Zoology Department, Faculty of Science, Suez Canal University, Egypt) under the standard conditions (food, temperature, humidity. and light as mentioned above) and used for educational as well as breeding purposes.

\section{Approximate estimation of $\mathrm{LD}_{50}$}

$\mathrm{LD}_{50}$ of $A$. amoreuxi venom (dissolved in $0.9 \% \mathrm{NaCl}, 10$ $\mathrm{mg} / \mathrm{kg}$ ) was carried out on mice and approximately estimated to be $1.1 \mathrm{mg} / \mathrm{kg}$ body weight. Eight animals were intraperitoneally (IP) injected with different venom doses $(D)$ and the survival time ( $\mathrm{T}$; time between scorpion venom injection and mouse death) of each mouse for 24 $\mathrm{h}$ was recorded. The data of $D$ versus $\mathrm{D} / \mathrm{T}$ was used to draw regression line and $\mathrm{LD}_{50}$ was calculated (Meier \& Theakston, 1986). Then, the estimated $\mathrm{LD}_{50}$ of mice (1.1 $\mathrm{mg} / \mathrm{kg}$ ) was converted into the equivalent $\mathrm{LD}_{50}$ for rats according to Paget and Barnes (1964).

\section{Peripheral and central analgesic activities of $A$. amoreuxi venom}

Antinociceptive activity of scorpion venom was examined using two methods (i) mice-writhing induced by acetic acid in mice test (peripheral analgesic activity) and (ii) rat tail immersion test (central analgesic activity).

\section{Assay of acetic acid inducing mice abdominal writhing}

Randomly, 24 mice have been divided into 4 groups ( $n=$ 6 animals/group). The first group (negative control group) was administered physiological saline $0.9 \% \mathrm{NaCl}$ $(10 \mathrm{~mL} / \mathrm{kg}, \mathrm{IP})$. The second group were injected (ip) with $1 / 10 \mathrm{LD}_{50}(0.11 \mathrm{mg} / \mathrm{kg})$ of scorpion venom. The third animal group received (ip) $1 / 5 \mathrm{LD}_{50}(0.22 \mathrm{mg} / \mathrm{kg})$ of scorpion venom (Salem et al., 2016). The fourth group received acetylsalicylic acid (aspirin $100 \mathrm{mg} / \mathrm{kg}$, ip) as a standard drug. In the animal groups 2,3 , and 4 , venom and standard drug were injected post-acetylsalicylic acid administration. Five minutes post-acetic acid administration, the number of abdominal writhing (constrictions) was counted for the period of $10 \mathrm{~min}$ in control and treated groups. The percentage of writhing inhibition was estimated using the following formula: TreatedControl $/$ Control $\times 100(\%$ inhibition $=\mathrm{Vt}-\mathrm{Vc} / \mathrm{Vc} \times$ 100) (Khan et al., 2010).

\section{Assay of rat's tail-immersion}

Twenty-four adult male albino rats (100-140 g) have been divided into 4 groups $(n=6 /$ group$)$. The first group (negative control group) was administered physiological saline $(10 \mathrm{mg} / \mathrm{kg}$, ip). The second and third animal groups were intraperitoneally injected with $1 / 10$ $\mathrm{LD}_{50}(0.0 .385 \mathrm{mg} / \mathrm{kg})$ and $1 / 5 \mathrm{LD}_{50}(0.0 .77 \mathrm{mg} / \mathrm{kg})$ of $A$. amoreuxi venom, respectively. The fourth group was injected with morphine chloride $(10 \mathrm{mg} / \mathrm{kg}$; ip, Sigma, Germany; Farsam, Amanlou, Dehpour, \& Jahaniani, 2000) as a standard analgesic drug. To conduct the assay, the rat was kept vertically to hang the tail which immersed up to $3 \mathrm{~cm}$ into a hot $\left(55 \pm 0.5^{\circ} \mathrm{C}\right)$ water bath. The time (s) taken to drag the tail from the water was 
defined as the reaction time $(\mathrm{Ta})$. The readings $(\mathrm{Ta})$ were recorded after $0,1,2,3,4$, and $5 \mathrm{~h}$ post-venom and morphine injection while $\mathrm{Tb}$ was defined as the reaction time of control group. Analgesic activity percentage was calculated according to the following equation: $\mathrm{Ta}-\mathrm{Tb} /$ $\mathrm{Tb} \times 100$ (Janssen, Niemegeers, \& Dony, 1963).

\section{Induction of pyrexia in rats using assay of Brewer's yeast}

Antipyretic effect of $A$. amoreuxi venom was examined using assay of Brewer's yeast in rats (Alpermann, 1972). Randomly, 24 rats have been divided into 4 groups $(n=$ 6 rats/group). Group I (negative control group) was administered physiological saline $(10 \mathrm{mg} / \mathrm{kg}$, ip). Groups II and III intraperitoneally injected with $1 / 10 \mathrm{LD}_{50}(0.385$ $\mathrm{mg} / \mathrm{kg})$ and $1 / 5 \mathrm{LD}_{50}(0.77 \mathrm{mg} / \mathrm{kg})$ of scorpion venom, respectively. Group IV received metamizole sodium as a standard drug ( $5 \mathrm{mg} / \mathrm{kg}$, ip). The induction of fever was induced through injection of $10 \mathrm{~mL} / \mathrm{kg} \mathrm{S}$. cerevisiae yeast (20\% aqueous suspension in physiological saline) at the neck nape of rats. To determine the pyretic response to yeast, the initial body temperature of rats was recorded rectally (using a digital thermometer) after $17 \mathrm{~h}$ from injection the yeast. Only rats that showed an elevated temperature (at least $0.5^{\circ} \mathrm{C}$ ) were included in the experiment. Then, scorpion venom and metamizole sodium were injected, and body temperature was measured at 1 $\mathrm{h}$ intervals for $5 \mathrm{~h}$ post-treatment.

\section{Antiinflammatory activity of $A$. amoreuxi venom using Brewer's yeast and carrageenan assays \\ Rats paw-edema induced by Brewer's yeast}

Antiinflammatory activity of $A$. amoreuxi venom was examined using rat paw edema-induced by Brewer's yeast. Twenty-four rats were divided randomly into four groups $(n=6)$. Edema in the right hind foot paw was induced by yeast injection. All rats were subcutaneously injected with $100 \mu \mathrm{L}$ of $20 \%$ aqueous suspension of yeast into the plantar surface of the right hind paw and physiological saline into left paw (Randall \& Selitto, 1957; Winter, Risley, \& Nuss, 1962). After 4 h, the paw thickness was measured using a skin caliper to detect the inflammatory process induced by yeast. The first group (negative control) was intraperitoneally injected with $200 \mu \mathrm{L}$ saline. The second and third groups were intraperitoneally injected with $1 / 10$ and $1 / 5 \mathrm{LD}_{50}$ of scorpion venom ( 0.385 and $0.77 \mathrm{mg} / \mathrm{kg}$, respectively). The fourth group was intraperitoneally injected with the standard drug of diclofenac sodium $(20 \mathrm{mg} / \mathrm{kg}$, Novartis, Switzerland; Goel, Singh, Mahajan, \& Kulkarni, 2004). The paw skin was re-measured at 3 and $6 \mathrm{~h}$ post-venom and drug administration. The antiinflammatory activity was estimated as percentage of paw edema inhibition using the equation of (mean of control-mean of treated)/ mean of control $\times 100$ (Vetrichelvan \& Jegadeesan, 2002).

\section{Mice paw-edema induced by carrageenan}

To confirm antiinflammatory activity of $A$. amoreuxi venom, the method of carrageenan-induced mouse paw oedema was applied (Gilligan \& Lovato, 1994; Girard, Verniers, Coppe, Pansart, \& Gillardin, 2008). Randomly, the mice were divided into four groups $(n=6$ animal/ group). The first group (negative control) was intraperitoneally injected with $200 \mu \mathrm{L}$ saline. The second (carrageenan control), third (1/5 $\mathrm{LD}_{50}$ of $A$. amoreuxi venom), and fourth (standard drug) animal groups have been injected (ip) with $200 \mu \mathrm{L}$ saline, $0.22 \mathrm{mg} / \mathrm{kg}$ scorpion venom, and $20 \mathrm{mg} / \mathrm{kg}$ diclofenac sodium (Goel et al., 2004), respectively. After $1 \mathrm{~h}$ post-treatment, $50 \mu \mathrm{L}$ of freshly prepared $1 \%$ carrageenan suspension $(50 \mathrm{mg} / 5$ $\mathrm{mL}$ of $0.9 \%$ saline) was subcutaneously administered into the right hind paw of mice (plantar surface). The thickness of mice paw was measured before carrageenan administration (zero time) and at $1 \mathrm{~h}$ intervals for $5 \mathrm{~h}$ using a skin caliper. The anti-inflammatory activity was estimated as the percentage of paw edema (induced by carrageenan) inhibition (Vetrichelvan \& Jegadeesan, 2002): Inhibition percent $=($ mean of control-mean of treated $) /$ mean of control $\times 100$. At the end of this experiment, mice were euthanized under anesthesia with diethyl ether $(C D$ Fine-Chem. Limited Co., India), and specimens of paw tissue (control and treated groups) were taken for histopathological examination (H\&E staining; $n=4$ /group).

\section{Statistical analysis}

Sigmaplot statistical software package (version 11) was used to perform all statistical analyses. The data (mean \pm standard errors) were statistically (at a probability criterion for significance $P<0.05$ ) analyzed using Student's unpaired $t$ test (for two groups comparisons) and one-way ANOVA (when comparing multiple groups) followed by a Dunnett post hoc test.

\section{Results \\ Acute toxicity of $A$. amoreuxi venom}

The approximate $\mathrm{LD}_{50}$ of $A$. amoreuxi venom was determined in mice $(1.1 \mathrm{mg} / \mathrm{kg}$, ip) and $1 / 5$ as well as $1 / 10$ $\mathrm{LD}_{50}$ were used in the assessment of pharmacological effects of scorpion venom.

\section{Peripheral and central analgesic activity of $A$. amoreuxi venom}

Writhing test was used to evaluate peripheral activity of scorpion venom in mice. In a dose-dependent manner, the venom was markedly $(P<0.05)$ decreased writhing behavior. The inhibition percent for the venom doses of $0.11 \mathrm{mg} / \mathrm{kg}\left(1 / 10 \mathrm{LD}_{50}\right), 0.22 \mathrm{mg} / \mathrm{kg}\left(1 / 5 \mathrm{LD}_{50}\right)$, and aspirin $(100 \mathrm{mg} / \mathrm{kg})$ were $57.894,65.038$, and 55.263 , respectively (Fig. 1). Also, the venom of A. amoreuxi revealed potential central analgesic activity in treated 


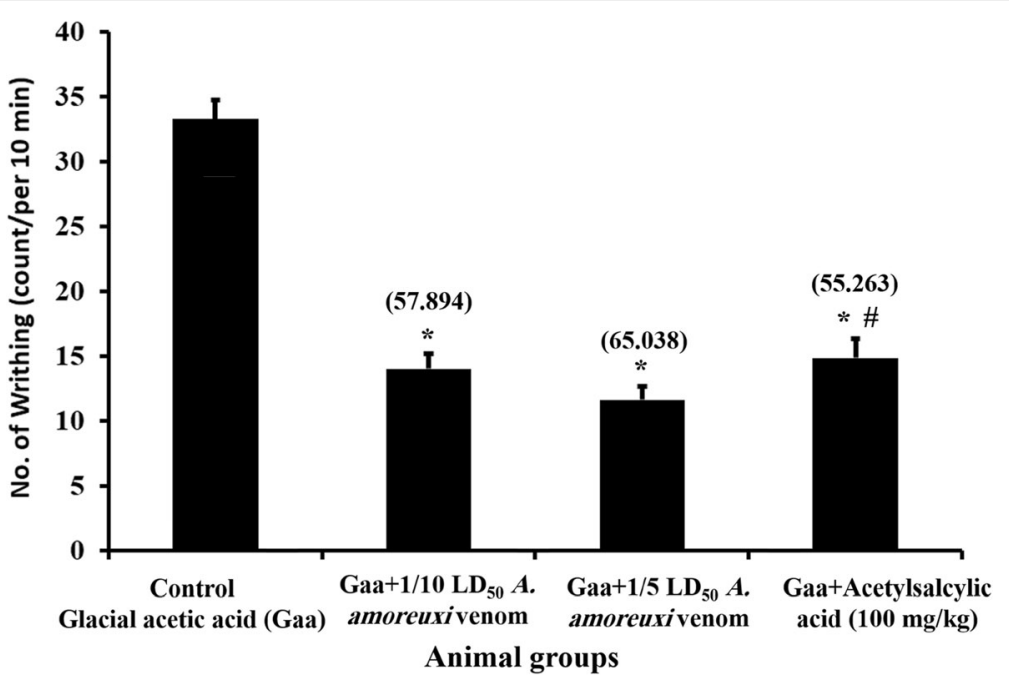

Fig. 1 Analgesic effect of $1 / 10$ and $1 / 5 L D_{50}$ of $A$. amoreuxi venom (0.11 and $0.22 \mathrm{mg} / \mathrm{kg}$, respectively) using glacial acetic acid (Gaa)-induced abdominal writhing in mice. Data are presented as mean \pm SEM ( 6 animals / group). $\left(^{*}\right)$ represents a significant difference between Gaa control and treated groups using Student's unpaired $t$ test $(p<0.05)$. (\#) represents a significant difference between all groups using one-way ANOVA ( $p$ $\leq$ 0.05). Values between brackets are pain inhibition percentage (\%PIP)

rats. The injection of both venom doses $(1 / 10$ and $1 / 5$ $\left.\mathrm{LD}_{50}\right)$ significantly increased $(P<0.05)$ the latency time of tail flick response of rats when compared to the control group (Fig. 2). The highest effect was recorded at the 2nd and 4th hour from injection $1 / 5 \mathrm{LD}_{50}$ of $A$. amoreuxi venom (percentage of inhibition reaching 147.06\%).

\section{A. amoreuxi venom antipyretic effect}

The data in Table 1 showed that subcutaneous administration of yeast suspension increased the rectal temperature of rats $\left(>38{ }^{\circ} \mathrm{C}\right)$ after $18 \mathrm{~h}$ of injection. Treatment with $A$. amoreuxi venom $\left(1 / 10\right.$ and $\left.1 / 5 \mathrm{LD}_{50}\right)$ significantly $(P<$ $0.05)$ decreased the rectal temperature of the rats. The venom antipyretic effect appeared from the 1st hour

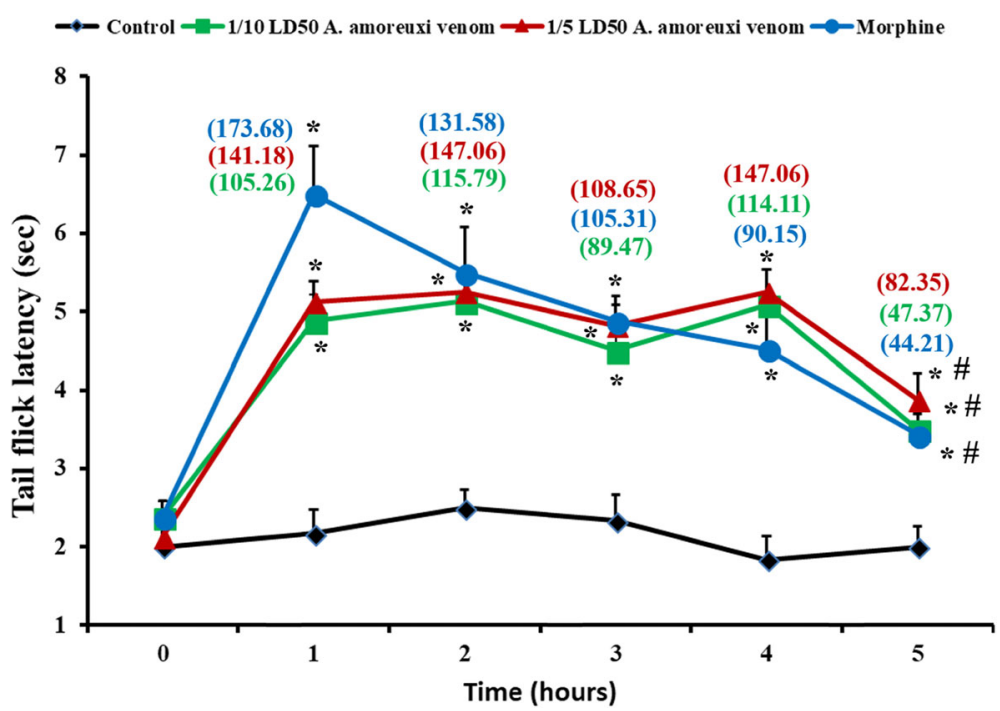

Fig. 2 Analgesic effect of $A$. amoreuxi venom using tail immersion test in rats. Effect of IP injection of 1/10 LD $(0.385 \mathrm{mg} / \mathrm{kg})$ and $1 / 5$ $\mathrm{LD}_{50}(0.77 \mathrm{mg} / \mathrm{kg})$ of venom on rat tail flick response. Data are presented as mean \pm SEM (6 animals/group). $\left({ }^{*}\right)$ represents a significant difference between normal control and treated groups using Students unpaired $t$ test $(p<0.05)$. (\#) represents a significant difference between all groups at time intervals in each treatment using one-way ANOVA $(p \leq 0.05)$. Values between brackets represent percentage of maximum analgesic effect 
Table 1 Antipyretic effect of $A$. amoreuxi venom using Brewer's yeast-induced pyrexia in rats

\begin{tabular}{|c|c|c|c|c|c|c|}
\hline \multicolumn{7}{|c|}{ Rectal temperature $\left(\mathrm{TR}^{\circ} \mathrm{C}\right)$ at different time intervals $(\mathrm{h})$} \\
\hline Treatment & $\mathrm{Oh}$ & 1st hour & 2nd hour & 3rd hour & 4th hour & 5th hour \\
\hline Yeast control & $38.05 \pm 0.0671$ & $38.05 \pm 0.085$ & $38.00 \pm 0.077$ & $38.00 \pm 0.052$ & $38.00 \pm 0.063$ & $38.07 \pm 0.056$ \\
\hline $\begin{array}{l}\text { Yeast }+1 / 10 \mathrm{LD}_{50}(0.385 \mathrm{mg} / \mathrm{kg}) \\
\text { A. amoreuxi venom }\end{array}$ & $38.04 \pm 0.061$ & $35.69 \pm 0.128^{*}$ & $36.54 \pm 0.318^{*}$ & $37.08 \pm 0.157^{*}$ & $36.925 \pm 0.170^{*}$ & $37.09 \pm 0.340^{*}$ \\
\hline $\begin{array}{l}\text { Yeast }+1 / 5 \mathrm{LD}_{50}(0.77 \mathrm{mg} / \mathrm{kg}) \\
\text { A. amoreuxi venom }\end{array}$ & $38.09 \pm 0.051$ & $35.55 \pm 0.159^{*}$ & $36.08 \pm 0.364^{*}$ & $36.25 \pm 0.194^{*}$ & $36.93 \pm 0.330^{*}$ & $37.03 \pm 0.33^{*}$ \\
\hline Yeast + metamizol & $38.01 \pm 0.055$ & $36.85 \pm 0.146^{* \#}$ & $36.30 \pm 0.168^{* \#}$ & $36.25 \pm 0.199^{* \#}$ & $36.43 \pm 0.067^{* \#}$ & $36.80 \pm 0.207^{*}$ \\
\hline
\end{tabular}

$(5 \mathrm{mg} / \mathrm{kg})$

Data are presented as mean \pm SEM (6 animals /group)

*A significant difference between yeast control and treated groups using Student's unpaired $t$ test $(p<0.05)$

${ }^{\#}$ A significant difference between all groups at time intervals using one-way ANOVA $(p \leq 0.05)$

until $5 \mathrm{~h}$ after the injection. However, the $1 / 5 \mathrm{LD}_{50}$ was more effective, and no significant difference was found between the two doses.

\section{Antiinflammatory effect of $A$. amoreuxi venom}

In the Brewer's yeast-induced paw oedema in rats, the paw thickness and percentages of inhibition by the $A$. amoreuxi venom and standard drug are shown in Table 2. Post-treatment of rats with $A$. amoreuxi venom (1/10 and $\left.1 / 5 \quad \mathrm{LD}_{50}\right)$ significantly inhibited the yeast-induced increase in the edema thickness of animal paws after $6 \mathrm{~h}$ by 13.375 and $16.375 \%$, respectively. In the carrageenaninduced paw oedema in mice, the data of paw thicknesses and inhibition (percent of change) induced by $1 / 5 \mathrm{LD}_{50}$ of A. amoreuxi venom and diclofenac sodium $(20 \mathrm{mg} / \mathrm{kg})$ are presented in Table 3. Scorpion venom showed a significant and time-dependent decrease of paw oedema starting from the 2nd hour until the 5th hour. A. amoreuxi venom reduced paw oedema with $72.46 \%$ (5th hour) postcarrageenan injection while diclofenac sodium recorded $36.23 \%$ inhibition at the same interval time (5th hour). Antiinflammatory effect of $A$. amoreuxi venom was also confirmed by histopathological examinations (Fig. 3). The dermal tissues of mice inflamed foot paw (induced by carrageenan) was markedly infiltrated with different inflammatory cells (macrophages, neutrophils, and lymphocytes;
Fig. 3b). The paw skin of animals treated with scorpion venom was moderately infiltrated with less inflammatory cells (macrophages, neutrophils, and lymphocytes) when compared with carrageenan control group (Fig. 3b). There was no acanthosis, and the thickness of epidermis was like normal but have hyperkeratosis. A. amoreuxi venom could decrease dermal edema, preserve the architecture of collagen fibers, and minify migration of PMF inflammatory cells into dermis.

\section{Discussion}

The peptides of scorpion venom exhibit various biological and pharmacological activities (Abdel-Rahman et al., 2015; Cheng et al., 2020; El-Bitar et al., 2019; Elrayess et al., 2019; Harrison et al., 2014; Zeng, Gerardo Corzo, \& Hahin, 2005). Peptides are the most abundant structures of scorpion venom and responsible for the neurotoxic as well as cytotoxic effects associated with scorpion sting (Jungo \& Bairoch, 2005). Many pharmaceutical companies are developing safer, specific and effective therapeutic agents (including steroidal and nonsteroidal (NSAIDS) antiinflammatory drugs) to treat pain, fever, and inflammatory diseases.

The peripheral and central analgesic effect of scorpion venom $\left(1 / 5\right.$ and $\left.1 / 10 \mathrm{LD}_{50}\right)$ was evaluated using writhing and tail immersion assays, respectively. In writhing

Table 2 Antiinflammatory effect of A. amoreuxi venom using Brewer's yeast-induced paw oedema in rats

\begin{tabular}{|c|c|c|c|}
\hline \multicolumn{4}{|l|}{ Paw thickness $(\mathrm{cm})$} \\
\hline Treatment & Initial & After $3 \mathrm{~h}$ & After $6 \mathrm{~h}$ \\
\hline Yeast control & $0.869 \pm 0.029$ & $0.825 \pm 0.02$ & $0.8 \pm 0.031$ \\
\hline Yeast + 1/10 LD $50(0.385$ mg/kg) A. amoreuxi venom & $0.894 \pm 0.023$ & $\begin{array}{l}0.894 \pm 0.023 \\
(6.788)\end{array}$ & $\begin{array}{l}0.693 \pm 0.020^{*} \\
(13.375)\end{array}$ \\
\hline $\begin{array}{l}\text { Yeast }+1 / 5 \mathrm{LD}_{50}(0.77 \mathrm{mg} / \mathrm{kg}) \\
\text { A. amoreuxi venom }\end{array}$ & $0.888 \pm 0.026$ & $\begin{array}{l}0.756 \pm 0.017^{*} \\
(8.364)\end{array}$ & $\begin{array}{l}0.669 \pm 0.019^{*} \\
(16.375)\end{array}$ \\
\hline $\begin{array}{l}\text { Yeast + diclofenac } \\
\text { sodium (20 mg/kg) }\end{array}$ & $0.825 \pm 0.015$ & $\begin{array}{l}0.719 \pm 0.024^{* \#} \\
(12.848)\end{array}$ & $\begin{array}{l}0.638 \pm 0.018^{* \#} \\
(20.25)\end{array}$ \\
\hline
\end{tabular}

Data are presented as mean \pm SEM (6 animals/group)

*A significant difference between yeast control and treated groups using Student's unpaired $t$ test $(p<0.05)$

\#A significant difference between all groups at time intervals $(3$ and 6 h) using one-way ANOVA $(p \leq 0.05)$. Values between brackets represent percentage of inflammation inhibition 
Table 3 Antiinflammatory effect of A. amoreuxi venom using carrageenan-induced paw edema in mice

\begin{tabular}{lllllll}
\hline Treatment & \multicolumn{2}{l}{ Paw thickness $\mathbf{( c m )}$} & & & \\
\cline { 2 - 7 } & 0 hour & 1st hour & 2nd hour & 3rd hour & 4th hour & 5th hour \\
\hline Normal control & $0.012 \pm 0.011$ & $0.005 \pm 0.008$ & $0.012 \pm 0.011$ & $0.005 \pm 0.008$ & $0.005 \pm 0.008$ & $0.012 \pm 0.011$ \\
Carrageenan control & $0.005 \pm 0.008$ & $0.100 \pm 0.041$ & $0.163 \pm 0.014$ & $0.15 \pm 0.011$ & $0.138 \pm 0.009$ & $0.138 \pm 0.009$ \\
Carrageenan + 1/5 LD 50 & $0.005 \pm 0.008$ & $0.131 \pm 0.055$ & $0.094 \pm 0.040^{*}$ & $0.081 \pm 0.035^{*}$ & $0.056 \pm 0.026^{*}$ & $0.038 \pm 0.010^{*}$ \\
A. amoreuxi venom & & & $(42.33)$ & $(46.0)$ & $(59.42)$ & $(72.46)$ \\
Carrageenan + diclofenac sodium (20 mg/kg) & $0.012 \pm 0.011$ & $0.081 \pm 0.032^{*}$ & $0.100 \pm 0.043^{* \#}$ & $0.094 \pm 0.038^{* \#}$ & $0.094 \pm 0.038^{* \#}$ & $0.088 \pm 0.035^{* \#}$ \\
& & $(19.0)$ & $(38.65)$ & $(37.33)$ & $(31.88)$ & $(36.23)$ \\
\hline
\end{tabular}

Data are presented as mean \pm SEM (6 animals/group)

*A significant difference between carrageenan control and each treated group using Student's unpaired $t$ test $(p<0.05)$

\#A significant difference between all groups at time intervals using one-way ANOVA $(p \leq 0.05)$. Values between brackets represent percentage of inflammation inhibition. $\Delta$ Paw thickness $(\mathrm{cm})=$ Paw thickness at each time interval - paw thickness at $0 \mathrm{~h}$ )

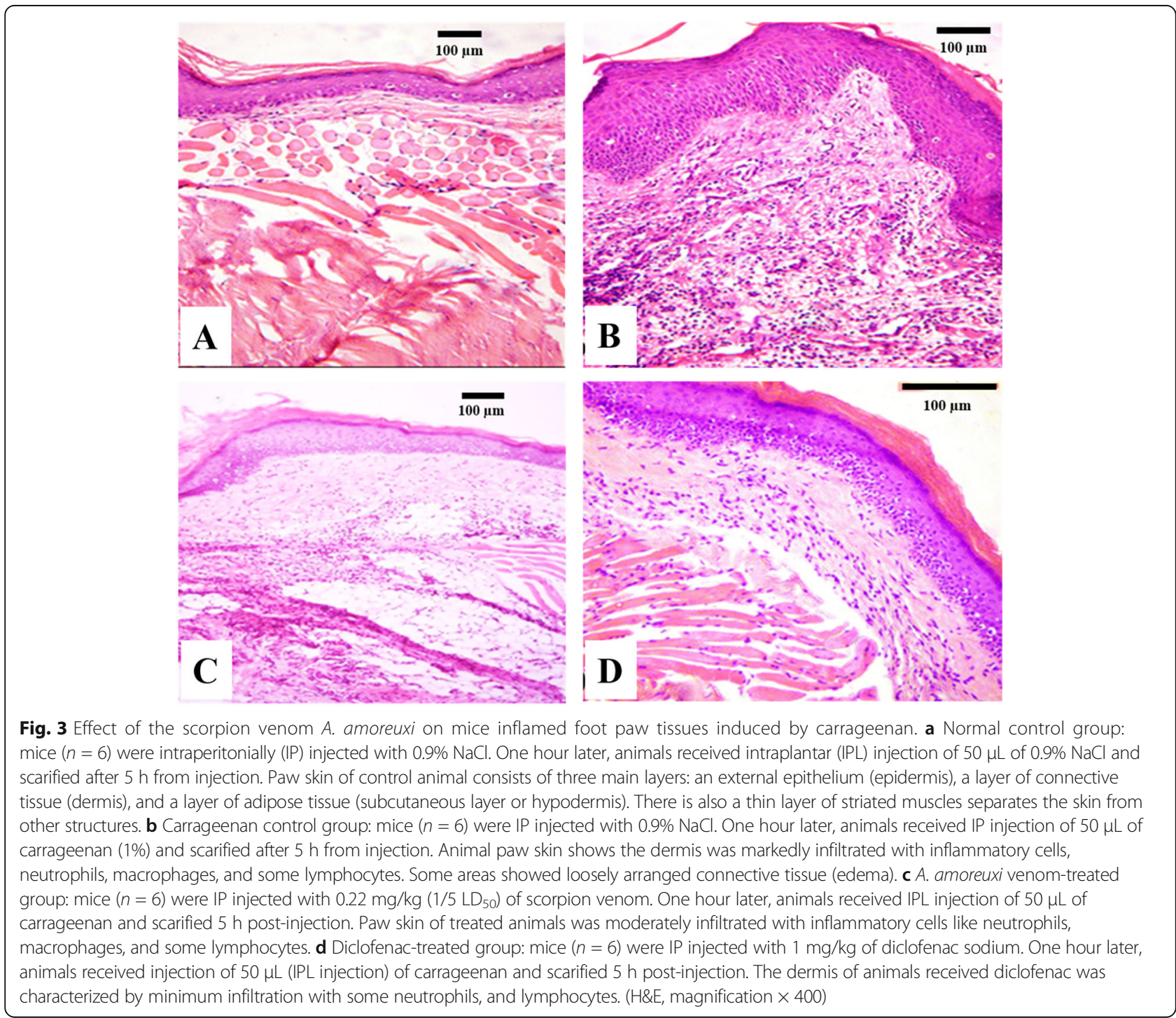


model, pain is indirectly produced through endogenous mediators such as bradykinin (which activates nociceptors), serotonin, histamine, cyclooxygenase, lipoxygenase products, and prostaglandin, which stimulated peripheral nociceptive neurons that are responsive to both narcotic analgesics and NSAIDs (Araujo et al., 2009; Khan et al., 2010). These signals can raise vascular permeability, decrease nociception threshold, and activate nociceptive terminal fibers (Julius \& Basbaum, 2001). Pretreatment of mice with $A$. amoreuxi venom significantly decreased the writhing response induced by acetic acid (in a dosedependent manner). It is important to mention that the peripheral analgesic effect of scorpion venom was very similar to the reference drug of aspirin. These findings suggest the potential of scorpion venom to decrease the release of inflammatory signals or block receptors, leading to a peripheral antinociceptive effect. Previously, there are several peptides with analgesic activity have been characterized from the venoms of various scorpions (Xiong et al., 1999; Tan et al., 2001ba and b; Shao et al., 2007; Cui et al., 2010; Liu et al., 2011; Shao et al., 2013). Of these, the long-chain neurotoxins BmK IT2 and BmK AS-1 (isolated from the scorpion venom of $B$. martensi Karsch) have been revealed potential antinociceptive effects modulating voltage-gated $\mathrm{Na}^{+}$channels of rat dorsal root ganglion (DRG) neurons (Tong, Zhang, Li, Zhou, \& Ji, 2000; Tan, Mao, Xiao, Zhao, \& Ji, 2001aa and b). Hoang et al. (2014) reported similar results with the venom of $H$. laoticus which showed antinociceptive activity via writhing assay.

Regarding the central analgesic activity of scorpion venom, both doses of $A$. amoreuxi venom significantly prolonged the reaction time of rats towards the thermal source. Consequently, the significant influence of scorpion venom on tail immersion response gives a further evidence of its central effect since the tail immersion is mainly a spinal reflex and considered to be selective for centrally acting analgesic agents (such as morphine) (Chattopadhyay et al., 2012; Sanchez-Mateo, Bonkanka, Hernandez-Perez, \& Rabanal, 2006). Shao et al. (2013) demonstrated that BmK AGAP-SYPU2, a new scorpion neurotoxin (similar to scorpion $\alpha$-sodium channels toxins) with dual functions with analgesic and antitumor activities, revealed potent analgesic effects against both peripheral (writhing test) and central (hot plate test) pain. Sensation of pathological pain appears following the excitability alteration (mainly regulated by voltage-gated sodium channels (VGSCs) of peripheral sensory neurons. BmK AGAP-SYPU2 might perform its analgesic activity by binding to certain receptor sites on VGSCs to inhibit their inactivation and block neural transmission. The same mode of action was reported for the recombinant scorpion neurotoxin of $\mathrm{BmK}$ AGAP (Liu et al., 2011). Accordingly, the results obtained from writhing and tail immersion assays suggested that $A$. amoreuxi venom has potent analgesic (both peripheral and central) activity. These findings are in agreement with Hoang et al. (2014) who reported that the venom of $H$. laoticus showed antinociceptive activity via peripheral and central pathways. Interestingly, these results were concomitant with the antipyretic activity of this venom. A. amoreuxi venom significantly decreased the elevated body temperature induced by Brewer's yeast in rats.

In addition to the analgesic and antipyretic activity, $A$. amoreuxi venom revealed prominent anti-inflammatory effect on the two induced models of acute inflammation (rats and mice paw-edema induced by yeast and carrageenan, respectively). The formation of paw edema resulted from a synergism between different inflammatory signals which leaded to increase blood flow (Zakaria et al., 2008). The early phase of rat paw edema is characterized by releasing of histamine, serotonin, and bradykinin followed by late phase which characterized by releasing of lysosome-like substances and prostaglandin (Abramson \& Weissman, 1989; Chattopadhyay et al., 2012). The significant decrease of paw edema thickness of treated rats (when compared to the yeast control group) revealed the anti-inflammatory activity of $A$. amoreuxi venom throughout the observation period up to $6 \mathrm{~h}$. Also, A. amoreuxi venom decreased thickness of mice paw by $42.33 \%$ at the 2 nd hour of carrageenan injection compared to diclofenac sodium that reduced the paw volume by $38.65 \%$. At the 5 th hour from carrageenan injection, scorpion venom and diclofenac sodium reduced the paw volume by $72.46 \%$ and $36.23 \%$, respectively. The result of post-treatment of scorpion venom demonstrated that this venom (at both doses) is effective in the late phase of inflammation (release of inflammatory mediators). The venom may induce its effect through inhibition of prostaglandin/other mediators released in the late phase. Ahmadi, Zare Mirakabadi, Hashemlou, and Hejazi (2009) found that treatment of rats with $M$. eupeus venom significantly reduced the score of arthritis index and the size region of tibio-tarsal joint. Treatment of rats with $M$. eupeus venom induced a significant reduction in the score of arthritis index and in the size of tibio-tarsal joint region. The same results have been reported by Hoang et al. (2014) by using the scorpion venom of $H$. laoticus.

Interestingly, histopathological investigation of mice foot paw confirmed potential antiinflammatory activity of $A$. amoreuxi venom. The venom reduced infiltration of inflammatory cells (including macrophages, lymphocytes, and neutrophils) when compared with carrageenan-non treated animal group. A. amoreuxi venom halted epidermal and dermal changes induced by carrageenan almost like with the standard drug of diclofenac. 


\section{Conclusion}

In conclusion, the scorpion venom of $A$. amoreuxi showed potent analgesic, antipyretic, and antiinflammatory activities using rats and mice animal models. Further proteomics and transcriptomics analyses studies are urgently needed to isolate and functionally characterize the active peptide(s) responsible for these activities.

\section{Abbreviations \\ A. amoreuxi: Androctonus amoreuxi; BmK: Buthus martensi Karsch; Ip: Intraperitoneally; NSAIDS: Non-steroidal antiinflammatory drugs; PMF: Primary myelofibrosis; VGSCs: Voltage-gated sodium channels}

\section{Acknowledgements}

Not applicable.

\section{Authors' contributions}

MAR designed and supervised the entire study, participated in analyzing the obtained data and wrote the initial draft of this article. NMS, WKT, MMD performed experimental work and contributed in analyzing the data. MLS reviewed the article and contributed in its coordination. All the authors (NMS, MLS, WKT, MMD, MAR) of this work have read and approved the final version of this manuscript.

\section{Funding}

No funding

\section{Availability of data and materials}

The datasets used and/or analyzed during the current study are available from the corresponding author on reasonable request.

\section{Ethics approval and consent to participate}

All experimental animals used in this investigation and experimental protocols were verified (Guide for the Care and Use of Laboratory Animals) and approved (number: 201503) by the Committee of Suez Canal University for Research Ethics.

\section{Consent for publication}

Not applicable.

\section{Competing interests}

The authors declare that they have no competing interests.

\section{Author details}

${ }^{1}$ Zoology Department, Faculty of Science, Suez University, Suez, Egypt. ${ }^{2}$ Zoology Department, Faculty of Science, Tanta University, Tanta, Egypt ${ }^{3}$ Pharmacology Department, Faculty of Veterinary Medicine, Suez Canal University, Ismailia 41522, Egypt. ${ }^{4}$ Zoology Department, Faculty of Science, Suez Canal University, Ismailia 41522, Egypt.

Received: 26 March 2020 Accepted: 9 September 2020

Published online: 17 September 2020

\section{References}

Abdel-Rahman, M. A., Quintero-Hernández, V., \& Possani, L. D. (2013). Venom proteomic and venomous glands transcriptomic analysis of the Egyptian scorpion Scorpio maurus palmatus (Arachnida: Scorpionidae). Toxicon, 74 193-207.

Abdel-Rahman, M. A., Harrison, P. L., \& Strong, P. N. (2015). Snapshots of scorpion venomics. Journal of Arid Environments, 112, 170-176.

Abramson, S. B., \& Weissman, G. (1989). The mechanism of action of nonsteroidal anti-inflammatory drugs. Arthritis and Rheumatism, 32, 1-9.

Ahmadi, M., Zare Mirakabadi, A., Hashemlou, M., \& Hejazi, M. (2009). Study on anti-inflammatory effect of scorpion (Mesobuthus eupeus) venom in adjuvantinduced arthritis in rats. Archives of Razi Institute, 64, 51-56.

Almaaytah, A., Zhou, M., Wang, L., Chen, T., Walker, B., \& Shaw, C. (2012) Antimicrobial/cytolytic peptides from the venom of the North African scorpion, Androctonus amoreuxi: biochemical and functional characterization of natural peptides and a single site-substituted analog. Peptides, 35(2), 291-299.
Alpermann, H. (1972). Berich, uber pharmakologische unter suchungen mit fenbendazole. Abteilung fur pharmacologie, 863, 1-9.

Altawil, H. J. A., Abdel-Rahman, M. A., El-Naggar, M. S., El-Khayat, Z. A., \& AbdelDaim, M. M. (2015). Analgesic, Antipyretic and Anti-Inflammatory Activities of the Egyptian Spitting Cobra, Naja Nubiae Venom. J Forensic Toxicol Pharmacol, 4, 1.

Araujo, F. L., Melo, C. T., Rocha, N. F., Moura, B. A., Leite, C. P., Amaral, J. F., ... de Sousa, F. C. (2009). Antinociceptive effects of(O-methyl)-N-benzoyl tyramine (riparin I) from Aniba riparia (Nees) Mez (Lauraceae) in mice. Naunyn Schmiedebergs Arch Pharmacol, 380(4), 337-344.

Chattopadhyay, C., Chakrabarti, N., Chatterjee, M., Chatterjee, S., Bhattacharyay, D., \& Ghosh, D. (2012). Evaluation of anti-inflammatory and analgesic activities of green tea decoction on experimental animal models. International Journal of Nutrition, Pharmacology, Neurological Diseases, 2(1).

Chen, B., \& Ji, Y. H. (2002). Antihyperalgesia effect of BmK AS, a scorpion toxin, in rat by intraplantar injection. Brain Research, 952(2), 322-326.

Cheng, Y., Sun, F., Li, S., Gao, M., Wang, L., Sarhan, M., Abdel-Rahman, M.A., Li, W., Kwok, H.F., Wu, Y., Cao, Z., (2020). Inhibitory Activity of a Scorpion Defensin BmKDfsin3 against Hepatitis C Virus. Antibiotics (Basel). 2020;9(1): E33. doi: https://doi.org/10.3390/antibiotics9010033.

Cui, Y., Guo, G. L., Ma, L., Hu, N., Song, Y. B., \& Liu, Y. F. (2010). Structure and function relationship of toxin from Chinese scorpion Buthus martensii Karsch (BmKAGAP): gaining insight into related sites of analgesic activity. Peptides, 31, 995-1000.

El-Bitar, A. M. H., Sarhan, M., Abdel-Rahman, M. A., Quintero-Hernandez, V., AokiUtsubo, C., Moustafa, M. A., ... Hotta, H. (2019). Smp76, a scorpine-like peptide isolated from the venom of the scorpion Scorpio maurus palmatus, with a potent antiviral activity against hepatitis $C$ virus and dengue virus. International Journal of Peptide Research and Therapeutics https://doi.org/10. 1007/s10989-019-09888-2.

Elrayess, R. A., Mohallal, M. E., El-Shahat, Y. M., Ebaid, H. M., Keith Miller, K., Strong, P. N., \& Abdel-Rahman, M. A. (2019). Cytotoxic effects of Smp24 and Smp43 scorpion venom antimicrobial peptides on tumour and non-tumour cell lines. International Journal of Peptide Research and Therapeutics https://doi. org/10.1007/s10989-019-09932-1.

Estrada-Gómez, S., Gomez-Rave, L., Vargas-Muñoz, L. J., \& van der Meijden, A. (2017). Characterizing the biological and biochemical profile of six different scorpion venoms from the Buthidae and Scorpionidae family. Toxicon, 130, 104-115.

Farsam, H., Amanlou, M., Dehpour, A. R., \& Jahaniani, F. (2000). Anti-inflammatory and analgesic activity of Biebersteinia multifida DC. root extract. Journal of Ethnopharmacology, 71, 443-447.

Ghosh, A., Roy, R., Nandi, M., \& Mukhopadhyay, A. (2019). Scorpion Venom-Toxins that Aid in Drug Development: A Review. International Journal of Peptide Research and Therapeutics, 25, 27-37.

Gilligan, J. P., \& Lovato, S. J. (1994). Modulation of carrageenan- induced hind paw edema Substance P. Inflammation, 18(3), 285-292.

Girard, P., Verniers, D., Coppe, M. C., Pansart, Y., \& Gillardin, J. M. (2008). Nefopam and ketoprofen synergy in rodent models of antinociception. European Journal of Pharmacology, 584, 263-271.

Goel, R. K., Singh, A., Mahajan, M. P., \& Kulkarni, S. K. (2004). Evaluation of anti-inflammatory and antihyperalgesic activity of some novel monocyclic b-lactam compounds in rats. Indian Journal of Pharmaceutical Sciences, 66, 87-91.

Guan, R. J., Wang, C. G., Wang, M., \& Wang, D. C. (2001a). A depressant insect toxin with a novel analgesic effect from scorpion Buthus martensii Karsch. Biochimica et Biophysica Acta, 1549(1), 9-18.

Guan, R. J., Wang, M., Wang, D., \& Wang, D. C. (2001b). A new insect neurotoxin AngP1 with analgesic effect from the scorpion Buthus martensii Karsch: purification and characterization. The Journal of Peptide

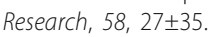

Harrison, P. L., Abdel-Rahman, M. A., Miller, K., \& Strong, P. N. (2014). Antimicrobial peptides from scorpion venoms. Toxicon, 88, 115-137.

Harrison, P. L., Abdel-Rahman, M. A., Strong, P. N., Tawfik, M. M., \& Miller, K. (2016). Characterisation of three alpha-helical antimicrobial peptides from the venom of Scorpio maurus palmatus. Toxicon, 117, 30-36.

Hoang, A. N., Vo, H. D., Vo, N. P., Kudryashova, K. S., Nekrasova, O. V., Feofanov, A. V., ... Utkin, Y. N. (2014). Vietnamese Heterometrus laoticus scorpion venom: evidence for analgesic and anti-inflammatory activity and isolation of new polypeptide toxin acting on Kv1.3 potassium channel. Toxicon, 77, 40-48. 
Janssen, P. A., Niemegeers, C. J. E., \& Dony, J. G. H. (1963). The inhibitory effect of fentanyl and other morphine-like analgesics on the warm water induced tail withdrawal reflex in rats. Arzneimittelforschung, 13, 502-507.

Julius, D., \& Basbaum, A. I. (2001). Molecular mechanisms of nociception. Nature, 13(413), 203-210

Jungo, F., \& Bairoch, A. (2005). Tox-Prot, the toxin protein annotation program of the Swiss-Prot protein knowledge base. Toxicon, 45, 293-301.

Khan, K. M., Ambreen, N., Mughal, U. R., Jalil, S., Perveen, S., \& Choudhary, M. I. (2010). 3-Formylchromones: potential antiinflammatory agents. European Journal of Medicinal Chemistry, 45, 4058-4064.

Liu, Y. F., Ma, R. L., Wang, S. L., Duan, Z. Y., Zhang, J. H., Wu, L. J., \& Wu, C. F. (2003). Expression of an antitumor-analgesic peptide from the venom of Chinese scorpion Buthus martensi Karsch in Escherichia coli. Protein Expression and Purification, 27(2), 253-258.

Liu, X. F., Li, C. L., Zhang, F., Jiang, X. M., Zhang, J. H., Wu, C. F., (2011). Effects of recombinant BmK AGAP on analgesic effects and voltage-gated sodium channels. Chin J Pharmacol Toxicol; 25(Suppl.):44.

Mamelak, A. N. (2011). Targeted antitumor therapy with the scorpion venom chlorotoxin. Drugs of the Future, 36, 615-625.

Meier, J., \& Theakston, R. D. G. (1986). Approximate $L D_{50}$, determinations of snake venoms using eight to ten experimental animals. Toxicon, 24(4), 395-401.

Paget, G. E. and Barnes, J. M., (1964). Toxicity tests in evaluation of drug activities pharmacometries (Laurence, D. R. and Bacharach, A. L. eds) Academic Press, London and New York.

Rajendra, W., Armugam, A., \& Jeyaseelan, K. (2004). Toxins in anti-nociception and anti-inflammation. Toxicon, 44(1), 1-17.

Randall, and Selitto (1957). Cited in "Selected topics in experimental pharmacology." by Sheath, U. K., Dadkar, N. K., Kamat, U. G., (1972). The Kothari book Dept. Parel, Bombay (India), (1972), $1^{\text {st }}$ ED. PP. 134.

Safavi-Hemami, H., Brogan, S.E., Olivera, B.M., (2019). Pain therapeutics from cone snail venoms: From Ziconotide to novel non-opioid pathways. Journal of Proteomics 6:190:12-20

Salem, M. L., Shoukny, N. M., Teleb, W. K., Abdel-Daim, M. M., \& Abdel-Rahman, M. A. (2016). In vitro and in vivo antitumor effects of the Egyptian scorpion Androctonus amoreuxi venom in an Ehrlich ascites tumor model. Springerplus 10, 5, 570.

Sanchez-Mateo, C. C., Bonkanka, C. X., Hernandez-Perez, M., Rabanal, R.M.,(2006). Evaluation ofthe analgesic and topical antiinflammatory effects of Hyperium reflexm L. fil. Journal of Ethnopharmacology. 11;107(1):1-6.

Shao, J. H., Kang, N., Liu, Y. F., Song, Y. B., Wu, C. F., \& Zhang, J. H. (2007). Purification and characterization of an analgesic peptide from Buthus martensii Karsch. Biomedical Chromatography, 21, 1266-1271.

Shao, J. H., Cuia, Y., Zhao, M. Y., Wub, C. F., Liub, Y. F., \& Zhang, J. H. (2013). Purification, characterization, and bioactivity of a new analgesic-antitumor peptide from Chinese scorpion Buthus martensii Karsch. Peptides, 10, 023.

Tan, Z. Y., Mao, X., Xiao, H., Zhao, Z. Q., \& Ji, Y. H. (2001a). Buthus martensi Karsch agonist of skeletal-muscle RyR-1, a scorpion active polypeptide: antinociceptive effect on rat peripheral nervous system and spinal cord, and inhibition of voltage-gated $\mathrm{Na}^{+}$currents in dorsal root ganglion neurons. Neuroscience Letters, 297(2), 65-68.

Tan, Z. Y., Xiao, H., Mao, X., Wang, C. Y., Zhao, Z. Q., \& Ji, Y. H. (2001b). The inhibitory effects of BmK IT2, a scorpion neurotoxin on rat nociceptive flexion reflex and a possible mechanism for modulating voltage-gated $\mathrm{Na}^{+}$ channels. Neuropharmacology, 40(3), 352-357.

Tong, Q. C., Zhang, Y., Li, D. P., Zhou, Z. N., \& Ji, Y. H. (2000). BmP02, one short chain scorpion peptide selectively blocks transient outward $\mathrm{K}^{+}$channel of adult rat ventricular myocyte, Regul. Peptides, 9, 85-92.

Vetrichelvan, T., \& Jegadeesan, M. (2002). Effect of alcoholic extract of Achyranthes Bidentatablume on Acute and subacute inflammation. Indian J Pharmacol, 34, 115.

Wang, C. G., He, X. L., Shao, F., Liu, W., Ling, M. H., \& Wang, D. C. (2001). Molecular characterization of an anti-epilepsy peptide from the scorpion Buthus martensii Karsch. Eur J Bio Chem., 268, 2480-2485.

Winter, C. A., Risley, E. A., \& Nuss, G. W. (1962). Carrageenan-induced oedema in hind paw of the rat as an assay for anti-inflammatory drugs, Proceeding of the society for Experimental Biology and Medicine, 111, 544-547.

Xiong, Y. M., Lan, Z. D., Wang, M., Liu, B., Liu, X. Q., Fei, H., ... Chi, C. W. (1999). Molecular characterization of a new excitatory insect neurotoxin with an analgesic effect on mice from the scorpion Buthus martensi Karsch. Toxicon, 37(8), 1165-1180.

Yu, J. K., Zhang, J. H., Wang, Q. Z., \& Liu, C. M. (1992). Effect of AEP obtained from the venom of Buthus martensii Karsch and its comparison with other similar drugs. Journal of Shenyang College of Pharmacy, 9, 200-204.
Zakaria, Z. A., Ghani, Z. D., Nor, R. N., Gopalan, H. K., Sulaiman, M. R., Jais, A. M., .. Ripin, J. (2008). Antinociceptive, antiinflammatory, and antipyretic properties ofan aqueous extract of Dicranopteris linearis leaves in experimental animal models. Journal of Natural Medicines, 62(2), 179-187.

Zeng, X., Gerardo Corzo, G., \& Hahin, R. (2005). Scorpiong venom peptides without disulfide bridges. IUBMB Life, 57(1), 13.

\section{Publisher's Note}

Springer Nature remains neutral with regard to jurisdictional claims in published maps and institutional affiliations.

\section{Submit your manuscript to a SpringerOpen ${ }^{\odot}$ journal and benefit from:}

- Convenient online submission

- Rigorous peer review

- Open access: articles freely available online

- High visibility within the field

- Retaining the copyright to your article

Submit your next manuscript at $\boldsymbol{\nabla}$ springeropen.com 